Hai là: Khi chuẩn bị hồ sơ rã tùy theo chất lượng phôi, khoang phôi chúng tôi tính thời gian rã, làm sao sau rã đến lúc chuyển đạt khoảng thời gian 3-4 tiếng, đặc biệt hạn chế tối đa chuyển phôi đã thoát màng.

Ba là: Chúng tôi thường xuyên kiểm soát chặt điều kiện phòng lab,

\section{KẾT LUÂNN}

Tỷ lê phôi sống sau rã đông của chúng tôi đat $99,85 \%$. Tỷ lệ $\beta$-hCG dương tính 74,79\% và tỷ lệ thai lâm sàng $67,12 \%$. Tỷ lệ làm tổ của phôi là 40,35\%.

Dựa trên các kết quả thu được chúng tôi cho rằng các trung tâm cần được đầu tư kỹ lưỡng về nhân lực, hệ thống nuôi cấy tốt và áp dụng thường quy việc nuôi và chuyển phôi nang. Tuy nhiên việc nuôii cấy và chuyển phôi nang chỉ ưu tiên các trường hợp tiên lượng tốt.

Tỷ lệ có thai lâm sàng khi chuyển 1 phôi là 71,43\%, bệnh nhân dưới 30 tuổi tiên lượng tốt nên tư vấn chuyển 1 phôi nhằm mục đích tránh đa thai và sinh non cũng như nhiều nguy cơ khác.

Tỷ lệ có thai lâm sàng còn liên quan đến một số yếu tố như tuổi người mẹ, kỹ thuật và thời điểm đông, rã, thời gian sau rã đông cho đến khi chuyển phôi cũng như các điều kiện phòng thí nghiệm.

\section{TÀI LIÊU THAM KHẢO}

1. Hiền Thu Thị Bùi, Kết quả chuyển phôi ngày 5 tại IVF Vạn Hạnh, IVF Expert meeting 8, 2012, 143-146.

2. Nguyến Thi Minh, Đánh giá hiêu quả chuyển phôi ngày 5, IVF Expert meeting 8, 2012, 55-62 5.

3. Ariel Weissman et al., Blastocyst culture and transfer: lessons from an unselected, difficult IVF population, RBM Online, 2008, Vol 17, No 2, 220-228

4. E.M.Kolibainakis, et al (2004) "Should we advise patients undergoing IVF to start cycle leading to a day 3 or a day 5 transfer" Human Reproduction Vol.19, No.Il pp. 2550-2554.

5. https://www.cochrane.org/CD002118/MEN STR_blastocyst-versus-cleavage-stage-embryotransfer-assisted-conception

6. Magli M, Gayle J, Kersti L et al. The atlas of human embryology from oocytes to preimplantation embryos. Oxford University Press, UK; 2012

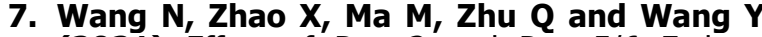
(2021) Effect of Day 3 and Day 5/6 Embryo Quality on the Reproductive Outcomes in the Single Vitrified Embryo Transfer Cycles. Front. Endocrinol. 12:641623. doi: 10.3389/ fendo.2021.641623

8. Zhang J, Wang $Y$, Liu HF, Mao XY, Chen QJ, Fan Y. Effect of In Vitro Culture Period on Birth Weight After Vitrified-Warmed Transfer Cycles: Analysis of 4,201 Singleton Newborns. Fertil Steril (2019) 111(1):97-104. doi: 10.1016/j. fertnstert.2018.10.006 PubMed Abstract | CrossRef Full Text | Google Scholar

\title{
TÌNH HÌNH THEO DÕI THAI PHỤ NHIỄM HIV/AIDS TẠI BỆNH VIỆN PHỤ SẢN TRUNG ƯO'NG
}

\section{TÓM TẮT}

Muc tiêu: Nhân xét thực trang khám thai của thai phu nhiễm HIV/AIDS tại BVPSTW. Phương pháp: Nghiên cứu hồi cứu mô tả. Kết quả: Tuổi trung bình của thai phu nhiếm HIV là $32,55 \pm 5,4$. Nhóm tuổi $\geq$ 35 tuổi chiếm tỉ lệ cao nhất 40,6\%. Thai phụ sinh con so là $31,5 \%$ và sinh con da là $68,5 \%$. Thai phu có khám và quản lý thai nghén là $91,5 \%$; trong đó tỷ lệ quản lý thai nghén tai BVPSTW là $42,4 \%$. Thời điểm phát hiện nhiếm HIV trước có thai là $73,3 \%$, trong khi có thai là $15,8 \%$ và ngay trước chuyển da là $10,9 \%$.Tỷ lệ điều trị dự phòng ARV cho thai phụ là $99,4 \%$. Thai phụ được điều trị ARV trước có thai là $70,9 \%$, trong khi có thai là $15,2 \%$ và khi chuyển dạ là $13,3 \%$. Kết

\footnotetext{
${ }^{1}$ Bệnh viện đa khoa Phúc Lâm

${ }^{2}$ Trường Đai hoc Y Hà Nôi

Chịu trách nhiệm chính: Đỗ Thu Huyền

Email: dothuhuyen301189@gmail.com

Ngày nhận bài: 26.7.2021

Ngày phản biên khoa họ: 27.9.2021

Ngày duyệt bài: 1.10.2021
}

\section{Đỗ Thu Huyền', Lê Thị Thanh Vân ${ }^{2}$}

luận: Thai phụ nhiễm HIV có khám và quản lý thai nghén chiếm tỳ lê cao $91,5 \%$. Thai phu phát hiên nhiếm HIV trước khi mang thai là 73,3\%. Tỷ lệ điều trị dự phòng ARV cho thai phụ là $99,4 \%$ và thai phụ điêu trị PLTMC từ trước khi có thai là 70,9\%.

Tư khóa: HIV, phòng lây truyền mẹ con.

\section{SUMMARY \\ MONITORING STATUS OF PREGNANT \\ WOMEN INFECTED WITH HIV/AIDS AT THE NATIONAL HOSPITAL OF OBSTETRICS AND GYNECOLOGY}

Objective: To assess the status of antenatal care of pregnant women infected with HIV/AIDS at the National Hospital of Obstetrics and Gynecology. Method: Descriptive retrospective study. Results: The mean age of pregnant women infected with HIV was 32.55 years (SD \pm 5.4 years). The age group over 35 years old accounted for the highest rate of $40.6 \%$. Pregnant women giving birth for the first time is $31.5 \%$ and $68.5 \%$ of women had had one more pregnancy. Pregnant women with pregnancy examination and management are $91.5 \%$, of which 
pregnancy management at the National Hospital of Obstetrics and Gynecology is $42.4 \%$. The time to detect HIV infection before pregnancy is $73.3 \%$, during pregnancy is $15.8 \%$ and right before labor is $10.9 \%$. The prevalence of ARV prophylaxis for pregnant women is $99.4 \%$. The proportion of women who received ARV before pregnancy is $70.9 \%$, during pregnancy is $15.2 \%$ and during labor is $13.3 \%$. Conclusion: HIV infected pregnant women with pregnancy examination and management accounted for a high rate of $91.5 \%$. Pregnant women detected HIV infection before pregnancy is $73.3 \%$. The prevalence of ARV prophylaxis for pregnant women is $99.4 \%$ and the rate of pregnant women receiving antiretroviral therapy before pregnancy is $70.9 \%$

Keywords: HIV, prevention of mother-child transmission.

\section{I. ĐặT VẤN ĐỀ}

Dịch HIV/AIDS là đại dịch nguy hiểm, là mối hiểm họa đối với tính mạng, sức khỏe con người. Tại Việt Nam, năm 2020 có 13.955 trường hợp nhiễm mới HIV và 2.160 trường hợp tử vong, trong khi những năm trước là 10.000 đến 11.000 trường hợp nhiễm mới. Mỗi năm có khoảng 2 triệu phụ nữ sinh con, với tỷ lệ nhiễm HIV vào khoảng $0,19 \%$ thì sẽ có hơn 3.800 phụ nữ mang thai nhiễm HIV sinh con. Để giảm nguy cơ lây truyên HIV từ mẹ sang con thì việc xét nghiệm HIV sớm và điều trị sớm bằng ARV là yếu tố có tính chất quyết định. Tại Việt Nam, các phác đồ phòng lây truyền mẹ con liên tục được cập nhật theo khuyến cáo của WHO nhằm hướng tới mục tiêu "Loại trừ lây truyền HIV từ mẹ sang con vào năm 2030". Chúng tôi thực hiện đề tài nghiên cứu: "Tinh hinh theo dõi thai phụ nhiễm HIV/AIDS tại Bệnh viện Phụ sản Trung ương".

\section{II. ĐỐI TƯỚNG VÀ PHƯƠNG PHÁP NGHIÊN CỨU}

2.1 Đối tượng nghiên cứu: Tất cả những thai phụ nhiễm HIV/AIDS và sinh con tại Bệnh viện Phụ sản Trung ương từ ngày 01/01/2019 đến 30/12/2020 thỏa mãn các tiêu chuẩn sau:

- Thai phụ được chẩn đoán HIV/ AIDS theo phương cách III của Bộ Y tế và sinh con tại Bệnh viện Phụ sản Trung ương.

- Những hồ sơ bệnh án đây đủ thông tin cân thu thập dựa theo mẫu bệnh án nghiên cứu.

\subsection{Phương pháp nghiên cứu}

2.2.1 Thiết kế nghiên cứu: Phương pháp nghiên cưu hồi cứu mô tả, dựa trên các số liệu thu thập được từ bệnh án nghiên cứu thai phụ nhiễm HIV/AIDS chuyển dạ đẻ tại BVPSTW.

2.2.2 Cõ mẫu nghiên cứu: Số bệnh nhân tham gia nghiên cứu được tính theo công thức:

$$
\mathrm{N}=Z_{(1-\propto / 2)}^{2} x \frac{p(1-p)}{(p, \varepsilon)^{2}}
$$

Trong đó: N: cõ mẫu cân nghiên cứu; $Z_{(1}^{2}$ cậy $\left.95 \% ; Z_{(1-\propto)} / 2\right)=1,96$.

a: mức ý nghĩa thống kê, tôi chọn $a=0,05$; $\varepsilon$ : sai số tương đối trong nghiên cứu là̀9\%.

p: tỷ lệ thai phụ phát hiện nhiễm HIV trước khi có thai theo nghiên cứu của Đỗ Mạnh Tùng là $77,8 \%, p=0,778^{1}$. Từ công thức tính cỡ mẫu trên, tôi tính được số đối tượng nghiên cứu $\mathrm{N}=135$.

2.2.3 Địa điểm nghiên cứu: Bệnh viện Phụ sản Trung ương.

\section{KẾT QUẢ NGHIÊN CỨU}

Trong nghiên cứu của chúng tôi, từ ngày $01 / 01 / 2019$ đến hết ngày 31/12/2020 tại BVPSTW có 165 thai phụ đủ tiêu chuẩn lựa chọn nghiên cứu và kết quả thu được như sau: cứu

Bảng 1. Đặc điểm của đôî tượng nghiên

\begin{tabular}{|c|c|c|c|}
\hline \multirow{2}{*}{$\begin{array}{c}\text { Tuối của } \\
\text { đối tượng } \\
\text { nghiên cứu }\end{array}$} & \multicolumn{2}{|c|}{ Địa chì } & \multirow[b]{2}{*}{ Tổng } \\
\hline & Hà Nội & $\begin{array}{c}\text { Các tính } \\
\text { khác }\end{array}$ & \\
\hline$<20$ tuổi & $1(0,6 \%)$ & $1(0,6 \%)$ & $2(1,2 \%)$ \\
\hline 20-24 tuổi & $3(1,8 \%)$ & $11(6,7 \%)$ & $14(8,5 \%)$ \\
\hline 25-29 tuổi & $14(8,5 \%)$ & $15(9,1 \%)$ & $29(17,6 \%)$ \\
\hline 30-34 tuổi & $20(12,1 \%)$ & $33(20 \%)$ & $53(32,1 \%)$ \\
\hline$\geq 35$ tuối & $23(13,9 \%)$ & $44(26,7 \%)$ & $67(40,6 \%)$ \\
\hline Tổng & $61(37 \%)$ & $104(63 \%)$ & $165(100 \%)$ \\
\hline
\end{tabular}

Tuối trung bình của thai phụ nhiếm HIV 32,55 $\pm 5,4$; thấp nhất 18 tuổi, cao nhất 44 tuổi. Nhóm tuổi hay gặp nhất ( $\geq 35$ tuổi) là 40,6\%. Thai phụ nhiếm HIV ở Hà Nội là 37\% và các tỉnh khác là 63\%.

Bảng 2. Tiền sử sán khoa của đôî tương nghiên cứu

\begin{tabular}{|c|c|c|c|}
\hline \multicolumn{2}{|c|}{ Tiên sử sản khoa } & $\begin{array}{c}\text { Số lượng } \\
\text { (n) }\end{array}$ & $\begin{array}{l}\text { Tỷ lệ } \\
(\%)\end{array}$ \\
\hline \multirow{4}{*}{$\begin{array}{l}\text { 1. Số } \\
\text { lânn } \\
\text { sinh } \\
\text { con }\end{array}$} & Con lần 1 & 53 & 31,5 \\
\hline & Con lân 2 & 77 & 46,6 \\
\hline & Con lần 3 & 24 & 15,2 \\
\hline & Con lân 4 & 11 & 6,7 \\
\hline \multirow{4}{*}{$\begin{array}{l}\text { 2. Số } \\
\text { lânn } \\
\text { hút } \\
\text { thai }\end{array}$} & Không hút thai & 83 & 50,3 \\
\hline & 1 lần & 42 & 25,5 \\
\hline & 2 lân & 32 & 19,4 \\
\hline & $\geq 3$ lân & 8 & 4,8 \\
\hline
\end{tabular}

Thai phụ sinh con lần 2 chiếm tỷ lệ cao nhất $46,6 \%$. Thai phụ có tiền sử hút thai 1 lần là 25,5\%, 2 lần là 19,4\% và $\geq 3$ lần là 4,8\%.

Bảng 3. Thời điểm phát hiện nhiễm HIV và quản lý thai nghén của đôi tượng nghiên cứu Quản lý thai nghén Thời điếm phát hiện nhiêm HIV Tống 
VIETNAM MEDICAL JOURNAL N² - OCTOBER - 2021

\begin{tabular}{|c|c|c|c|c|c|}
\hline & $\begin{array}{c}\text { Trước có } \\
\text { thai }\end{array}$ & $\begin{array}{c}\text { Trong khi } \\
\text { có thai }\end{array}$ & $\begin{array}{c}\text { Ngay trước } \\
\text { chuyển dạ }\end{array}$ & \\
\hline \multirow{3}{*}{$\begin{array}{c}\text { Có } \\
\text { khám } \\
\text { thai }\end{array}$} & PSTW & $56(33,9 \%)$ & $13(7,9 \%)$ & $1(0,6 \%)$ & $70(42,4 \%)$ \\
\hline & BV tỉnh-huyện & $40(24,2 \%)$ & $6(3,6 \%)$ & $2(1,2 \%)$ & $48(29,1 \%)$ \\
\hline & PK tư' & $21(12,8 \%)$ & $6(3,6 \%)$ & $6(3,6 \%)$ & $33(20 \%)$ \\
\hline \multirow{2}{*}{\multicolumn{2}{|c|}{$\begin{array}{c}\text { Không khám thai } \\
\text { Tống }\end{array}$}} & $4(2,4 \%)$ & $1(0,6 \%)$ & $9(5,5 \%)$ & $14(8,5 \%)$ \\
\hline & & $121(73,3 \%)$ & $26(15,8 \%)$ & $18(10,9 \%)$ & $165(100 \%)$ \\
\hline
\end{tabular}

- Thai phụ có khám và quản lý thai nghén là 91,5\%; trong đó khám thai tại BVPSTW chiếm tỷ lệ cao nhất $42,4 \%$. Thai phụ phát hiện nhiễm HIV trước có thai là $73,3 \%$, trong khi có thai là $15,8 \%$ và ngay trước chuyển da là $10,9 \%$.

- Trong số 26 thai phụ phát hiện nhiễm HIV trong khi có thai, tỷ lệ được phát hiện tại BVPSTW là cao nhất 7,9\%. Có 18 thai phụ phát hiện nhiễm HIV khi chuyển dạ, trong đó 5,5\% không khám thai và tỷ lệ thai phụ khám tại phòng khám tư là cao nhất 3,6\%. $(p<0,05)$.

Bảng 4. Tình hình điều trị $A R V$ và thời điểm điều trị ARV của đôi tượng nghiên cứu

\begin{tabular}{|c|c|c|c|}
\hline \multicolumn{2}{|c|}{$\begin{array}{l}\text { 1. Tình hình điêu trị } \\
\text { ARV }\end{array}$} & $\begin{array}{l}\text { Số lượng } \\
\text { (n) }\end{array}$ & $\begin{array}{l}\text { Tỷ lề } \\
(\%)\end{array}$ \\
\hline \multicolumn{2}{|c|}{ Có } & 164 & 99,4 \\
\hline & & 1 & 0,6 \\
\hline \multicolumn{4}{|c|}{ 2. Thời điếm điều tri ARV } \\
\hline \multicolumn{2}{|c|}{ Trước có thai } & 117 & 70,9 \\
\hline \multirow{3}{*}{$\begin{array}{c}\text { Trong khi } \\
\text { có thai } \\
\text { Naay tru }\end{array}$} & $<12$ tuần & 3 & 1,9 \\
\hline & $\geq 12$ tuần & 22 & 13,3 \\
\hline & Ngay trước chuyến da & 22 & 13,3 \\
\hline
\end{tabular}

Có 164/165 thai phụ điều trị ARV chiếm $99,4 \%$ và $1 / 165$ thai phụ không điều trị ARV chiếm $0,6 \%$. Thai phụ được điêu trị ARV trước khi có thai chiếm tỷ lệ cao nhất là 70,9\%.

\section{BÀN LUÂN}

Qua nghiên cứu chúng tôi thấy thai phụ trong độ tuổi 20-34 tuổi là 58,2\% vànhóm tuối $\geq 35$ tuổi là $40,6 \%$. Tuổi trung bình của thai phu nhiễm HIV là $32,55 \pm 5,4$; thấp nhất là 18 tuổi, cao nhất là 44 tuổi. Tuối trung bình của thai phụ nhiễm HIV trong nghiên cứu của chúng tôi cao hơn các nghiên cứu trước và sư phân bố theo nhóm tuổi cũng có sự thay đổi. TheoLương Tâm Phúc, tuổi trung bình của thai phụ nhiễm HIV là 26,4 × 4,4; độ tuổi 20-34 là 95,29\%; nhóm tuổi $\geq 35$ tuối là $3,53 \%^{2}$. Nghiên cứu của Mai Thị Anh, tuổi trung bình của thai phụ là 29,14 $\pm 4,4$; độ tuổi 20- 34 là $88,1 \%$; nhóm tuổi $\geq 35$ tuổi là $10,9 \%^{3}$. Phụ nữ sinh con khi tuổi cao làm tăng nguy cơ cho thai như sảy thai, thai dị tật, đẻ non, thai chậm phát triển trong tử cung... Đồng thời, thai phụ lớn tuổi có thể phải đối mắt với các nguy cơ như đái tháo đường, tăng huyết áp, tiền sản giật... Đặc biệt, phư nữ trên 35 tuổi mang thai khi kèm theo nhiếm HIV/AIDS càng tăng nguy cơ ảnh hưởng đến sức khỏe của me và thai. Tuy nhiên, nhờ công tác phòng chống HIV/AIDS và sự phát triển của ngành y tế nên hiểu biết về HIV/AIDS ngày càng được nâng cao, các biện pháp PLTMC được áp dụng rộng rãi và đạt được những hiệu quả đáng kể. Phụ nữ nhiễm HIV được tư vấn và tạo điều kiện tiếp cận các biện pháp PLTMC nên nhu câu có con của họ ngày càng tăng.

Qua bảng 1 trong nghiên cứu, tỷ lệ thai phụ nhiễm HIV sinh tại BVPSTW ở các tỉnh khác (63\%) cao hơn ở Hà Nôi (37\%). BVPSTW là bệnh viện đầu ngành của cả nước, đặc biệt là khu vực miền Bắc nên số lượng thai phụ nói chung cũng như thai phụ nhiễm HIV nói riêng ưu tiên lựa chọn bênh viện để theo dõi thai nghén, làm số lương bệnh nhân ở ngoại tỉnh sinh tại bệnh viện ngày càng tăng. Đồng thời, phương tiện giao thông đi lại giữa các tỉnh lên Hà Nội ngày càng thuận lợi, nhiều thai phụ ở các tỉnh lân cận, thậm chí các tỉnh xa (Hà Giang, Cao Bằng, Thanh Hóa, Nghệ An...) có xu hướng sinh tại BVPSTW nhiều hơn bệnh viện tuyến tỉnh.

Trong nghiên cứu của chúng tôi thai phụ nhiễm HIV đẻ con so là $31,5 \%$ thấp hơn của Đố Thị Minh Hiền (2010) là $59 \%{ }^{4}$. Thai phụ sinh con lần 2 , lần 3 , lần 4 lần lượt là $46,6 \% ; 15,2 \%$ và $6,7 \%$. So sánh với nghiên cứu của Mai Thị Anh (2012-2013) tỷ lệ thai phụ sinh con lần 3 là $7,4 \%$ và không có thai phụ sinh con lần $4^{3}$. Theo Đỗ Manh Tùng (2015) thai phụ sinh con lần 3 là 12,35\% và lần 4 là $1,23 \%{ }^{1}$. Qua đây, chúng tôi thây thai phụ nhiễm HIV đẻ nhiều con có xu hướng ngày càng tăng, đáng chú ý là thai phụ sinh con lần 3, lân 4 tăng cao so với những năm trước.

Ở Việt Nam, tỷ lệ nạo hút thai còn khá cao, nhu câu tránh thai chưa đáp ứng đầy đủ với phụ nữ ở đô tuổi sinh đẻ. Trong nghiên cứu của chúng tổi, số thai phụ có tiền sử hút thai vẫn tương đối cao, cao nhất là nhóm thai phụ có tiền sử hút thai 1 lần chiếm 25,5\%. Do vậy, cần đẩy manh công tác truyền thông kế hoạch hóa gia đình, tư vấn và sử dụng các biện pháp tránh thai để giảm tỷ lệ nạo phá thai nói chung, đặc biệt 
đối với phụ nữ nhiễm HIV.

Quản lý thai nghén có vai trò quan trọng trong công tác chăm sóc sức khỏe sinh sản, cũ̃ng là bước đầu trong chăm sóc sức khỏe bà mẹ và thai nhi. Qua nghiên cứu, chúng tôi thấy thai phụ nhiễm HIV được quản lý thai nghén là $91,5 \%$ có chiều hướng tăng hơn so với những năm trước taii BVPSTW như: nghiên cứu của Đố Thị Minh Hiền (2010-2014) thai phụ nhiếm HIV có khám thai là $86,2 \%{ }^{4}$, Phạm Văn Chung (2013-2014) là $78,8 \%{ }^{5}$. Điều này thể hiện sự thành công trong công tác tuyên truyền chăm sóc sức khỏe ban đầu cho bà mè và trẻ em, giúp thai phụ nhiễm HIV/AIDS ngày càng có ý thức trong việc quản lý thai nghén. Đa số các thai phụ đã có ý thức chăm sóc sức khỏe bản thân và thai nhi thể hiên ở việc có quản lý thai nghén tại các cơ sở y tế: tại BVPSTW là 42,4\%; bệnh viện tỉnh-huyện là $29,1 \%$ và phòng khám tư là $20 \%$. Tỷ lệ thai phụ quản lý thai nghén tại phòng khám tư nhân tương đối cao, chứng tỏ mạng lưới y tế tư nhân cũng góp phần không nhỏ trong công tác quản lý thai nghén.

Tình hình quản lý thai nghén sẽ ảnh hưởng đến khả năng phát hiện sớm thai phụ nhiễm HIV. Phát hiện sớm tình trạng nhiễm HIV ở phụ nữ mang thai có ý nghĩa rất quan trọng, giúp cho người phụ nữ tự quyết định các vấn đề sinh con và thực hiện tốt các biện phápPLTMC. Qua bảng 3 trong nghiên cứu, có $73,3 \%$ thai phụ phát hiện nhiễm HIV trước có thai nhưng vẫn quyết định sinh con, điêu này thể hiện công tác truyền thông PLTMC ngày càng lan rộng, mạng lưới y tế ngày càng được nâng cao và nhận thức của phụ nữ mang thai nhiễm HIV tốt hơn. Họ sớm tiếp cận với các dịch vụ tư vấn và biết được lợi ích của việc điều trị bằng thuốc kháng virus ARV sớm sẽ cải thiện sức khỏe bản thân cũng như giảm tỷ lệ lây truyền HIV từ mẹ sang con. Tỷ lệ phụ nữ mang thai phát hiện nhiếm HIV sớm ngày càng tăng và phát hiện khi chuyển da ngày càng giảm so với nghiên cứu của Nguyễn Viết Tiến và cộng sự (2005-2008) là 45,3\% $\%^{6}$ và Mai Thị Anh (2012-2013) là 15,8\% ${ }^{3}$. Theo nghiên cứu của chúng tôi, thai phụ nhiễm HIV được phát hiện ngay khi chuyển dạ là ít nhất $10,9 \%$. Trong số 18 thai phụ phát hiển nhiếm HIV ngay trước chuyển dạ, có 9 trường hợpquản lý thai nghén từ khi có thai nhưng mới được phát hiện nhiếm HIV khi chuyển dạ, trong đó $6 / 9$ thai phụ khám thai tại phòng khám tư chiếm tỷ lệ cao nhất. Điều này cho thây vẫn còn những thai phụ đi khám và quản lý thai từ khi có thai nhưng có thể chưa được tư vấn làm xét nghiệm HIV hoặc họ không đồng ý làm xét nghiệm mặc dù đã được tư vấn. Hiện nay, ở Việt Nam phần lớn phụ nữ có thai đi khám thai từ khá sớm (trước 12 tuần) nhưng xét nghiệm sàng lọc HIV lại thường không được thực hiện sớm ngay từ lần khám thai đầu tiên. Tỷ lệ phụ nữ mang thai được làm xét nghiệm HIV trong quá trình mang thai chưa cao (ở mức 52\%) khiến cho công tác PLTMC chưa phát huy hiệu quả cao nhất?

Công tác quản lý thai nghén cũng góp phần quan trọng vào thời điểm điêu trị ARV cho thai phụ. Thời điểm phát hiện nhiễm HIV sẽ ảnh hưởng tới thời điểm dùng thuốc PLTMC sớm hay muộn. Trẻ sinh ra từ những bà mẹ bắt đầu điều trị ẢRV trước và trong khi mang thai có tỷ lệ lây nhiê̂m HIV từ me thấp hơn ${ }^{8}$. Điêu trị thuốc kháng Retrovirus ngay từ trong thai kỳ có hiệu quả cao hơn so với điều trị khi chuyển dạ. Do đó, nếu phụ nữ có thai nhiễm HIV/AIDS được dùng thuốc dự phòng ở tuổi thai càng sớm thì khả năng lây truyền me con càng thấp ${ }^{9}$. Qua bảng 4trong nghiên cứu, tỳ lệ thai phụ nhiễm HIV/AIDS điều trị dự phòng bằng ARV là $99,4 \%$ tương tự Đỗ Thị Minh Hiền là $97,5 \%{ }^{4}$ và Đỗ Mạnh Tùng năm 2015 là 99,7\% ${ }^{1}$. Thai phụ nhiễm HIV được điều trị PLTMC từ trước có thai là $70,9 \%$, trong khi có thai là $15,2 \%$ và ngay trước chuyển da là 13,3\%. Nghiên cứu của Mai Thị Anh, thời điểm điều trị ARV của thai phụ trước khi có thai là $43,8 \%$, trong khi có thai là $38,9 \%$ và khi chuyển dạ là $14,3 \%{ }^{3}$. Theo Đố Mạnh Tùng các tỷ lệ trên lần lượt là $29,6 \% ; 57,8 \%$ và $12,3 \%{ }^{1}$. So sánh kết quả của các nghiên cứu trên cho thây thời điểm điều trị PLTMC của thai phụ nhiễm HIV có sự thay đổi. Tỷ lệ thai phụ được điều trị ARV từ trước có thai tăng lên đáng kể do họ có sự chủ động tiếp cận các dịch vụ PLTMC. Cùng với sự phát triển của xã hội và nền y học tiến bộ thì những người nhiễm HIV trước và khi mang thai đã được tiếp cận, tư vấn về vấn đề điều trị dự phòng lây truyền me con. Điều này góp phần làm giảm đáng kể khả năng lây truyền HIV trong cộng đồng và giảm lây truyền mẹ con.

\section{KẾT LUẬN}

Thai phụ nhiễm HIV có khám và quản lý thai nghén chiếm tỷ lệ cao là $91,5 \%$.Thai phụphát hiện nhiếm HIV trước khi mang thai là 73,3\%.Tỷ lệ điều trị dự phòng ARV cho thai phụ là $99,4 \%$ và thai phụ điều trị PLTMC từ trước khi có thai là $70,9 \%$.

\section{TÀI LIÊUU THAM KHẢO}

1. Đỗ Mạnh Tùng. Nghiên cựu thái độ xử trí trong chuyển dạ ở sản phụ nhiễm HIV/AIDS tại Bệnh 
viện Phụ sản Trung Ương trong hai giai đoạn 2005-2015. Luận văn thạc sỹ y học, trường Đại hoc Y Hà Nôii, 2016.

2. Lương Tâm Phúc. Nhận xét việc theo dõi thai và xử trí sản phu nhiễm HIV đẻ tai Bênh viên Phu sản Hà Nội trong 5 năm 2006-2010. Luận văn bác sĩ chuyên khoa cấp II, trường Đại học Y Hà Nội, 2011.

3. Mai Thi Anh. Nghiên cứu thái đô xử trí sản khoa ở sản phụ nhiễm HIV/AIDS đẻ tại Bệnh viện Phụ sản Trung ương trong 2 năm 2012-2013. Luần văn thăc sỹ y học, trường Đại học Y Hà Nội, 2014.

4. Đố Thi Minh Hiền. Nghiên cứu môt số đăc điểm và thực trạng tiếp cận dịch vụ phòng lây truyên HIV tứ mẹ sang con tại Bệnh viện Phụ sản Trung ương 2010-2014.Luâan văn thạc sỹ y học, trường Đại học Y Hà Nội, 2015.

5. Pham Văn Chưng. Thực trang theo dõi và điều trị bệnh nhi nhiếm HIV đẻ tại Bệnh viện Phụ sản
Trung ương năm 2013-2014. Luân văn bác sĩ chuyên khoa II, trường Đại học Y Hà Nội, 2016.

6. Nguyên Viết Tiến, Đố Quan Hà, Phan Thi Thu Nga. Bước đầu đánh giá và hiệu quả điểu tri phòng lây nhiễm HIV từ me sang con tại Bệnh viện Phu sản Trung ương từ 9/2005-2/2008. Đai hội toàn quốc và hội nghị khoa học Hội Sản phụ khoa và sinh đẻ có kế hoạch Việt Nam lần thứ XVI, tr.112-120, 2009.

7. Bô Y tế - Cuc phòng chống HIV/AIDS, Báo cáo tình hình nhiếm HIV/AIDS năm 2020.

8. Agabu A, Christa F.W, Klerk M, et al. Nationallevel effectiveness of ART to prevent early mother to child transmission of HIV in Namibia. Plos one. 2020;15(11).

9. WHO. Weekly epidemiological record, Global situation off the HIV/AIDS pandemic, end 2003. Weeky Epidmiological record. 2003;49,417-424.

\title{
THỰC TRANG SỬ DUNG DICH VỤ Y TẾ CỦA NGƯỜII DÂN TẠI MộT SỔ TỈNH MIỀN BẮC NĂM 2020
}

\author{
Nguyễn Thị Thu Hường ${ }^{1}$, Đàm Thị Ngọc Anh ${ }^{1}$, Lê Đình Luyến ${ }^{1}$, \\ Đoàn Ngọc Thủy Tiên ${ }^{1}$, Phạm Thị Thu Trang ${ }^{1}$, Nguyễn Sử Minh Ngọc ${ }^{2}$
}

\section{TÓM TẮT}

Nghiên cứu mô tả cắt ngang trên 348 người dân tại Bắc Ninh và Cao Bằng để mô tả về thực trang sử dụng dịch vụ y tế. Kết quả cho thấy phần lớn đối tượng tự mua thuốc để điều trị $(76,6 \%)$, điều trị ngoại trú $(23,7 \%)$. 95,5\% đối tượng sử dụng bảo hiếm y tế khi điều trị nôi trú và $50 \%$ sử dung bảo hiểm y tế khi điều trị ngoai trú. Một số yếu tố liển quan: nữ giới có xu hướng sử dung dich vu cao hơn 1,9 lần $(\mathrm{p}<0,05)$; người sống với vợ/chồng/người yêu cao hơn 2,19 lần so với người sống độc thân $(p<0,05)$ và những người mắc bệnh trong 3 tháng qua sử dụng dịch vụ gấp 4,09 lần so với người không có vấn đề sức khỏe $(p<0,001)$. Cần có thêm các nghiên cứu với quy mô rộng hơn và phân tích, đánh giá sâu hơn về sử dụng dịch vụ y tế.

Từ khóa: sử dụng dịch vụ y tế, miền Bắc

\section{SUMMARY}

\section{SITTUATION OF HEALTH SERVICES USAGE AMONG PEOPLE IN SOME VIETNAMESE NORTHERN PROVINCES IN 2020}

A cross-sectional study among 348 people in Bac Ninh and Cao Bang to describe the situation of using health services àn some related factors. Results showed that the most of health services usage among people were self-treatment $(76.6 \%)$ and outpatient

\footnotetext{
${ }^{1}$ Viện Đào tạo Y học dự phòng và Y tế công cộng ${ }^{2}$ Trường Đai hoc Y Hà Nôi

Chịu trách nhiệm chính: Nguyễn Thị Thu Hường

Email: ntth@hmu.edu.vn

Ngày nhận bài: 29.7.2021

Ngày phản biện khoa học: 30.9.2021

Ngày duyệt bài: 6.10.2021
}

treatment (23.7\%). $95.5 \%$ of participants use health insurance for inpatient treatment and $50 \%$ for outpatient treatment. Some related factors: females were higher 1.9 times than males $(p<0.05)$; People living with their spouses / lovers were more 2.19 times higher than those living alone $(p<0.05)$ and those suffer from diseases in the past 3 months used the service 4.09 times than those without have health problems $(p<0.001)$. There will be a need for more extensive research and in-depth analysis and assessment of the use of health services.

Keywords: health services usage, northern provinces

\section{I. ĐĂT VẤN ĐỀ}

Sức khỏe là vốn quý nhất của con người, chăm sóc sức khỏe cộng đồng là một khía cạnh quan trọng trong ngành $Y$ tế công cộng. Vấn đề sức khỏe người dân tăng lên kéo theo nhu câu về sử dụng dịch vụ y tế từ đó cũng tăng lên chứ không chỉ đơn thuân là do già hóa dân số, các bệnh truyền nhiễm và tai nan, điều kiên sống tốt hởn đòi hỏi dich vu y tế phải tốt hơn và tiên nghi hơn. Tỷ lệ cung ứng dịch vụ y tế trong 10 năm đã tăng từ 27,4\% đến 31,1\% (2008- 2018). Tỷ lệ sử dụng dịch vụ y tế trên cả nước đã tăng 1,2 lẩn (2012-2018)[1]. Măc dù vây, tự điều trị khi ốm đau hay tai nan thương tích vẫn là một hành vi rất phổ biến ở nước ta, có tới 45,9\% người dân tự mua thuốc về điêu trị khi mắc bệnh, gân $70 \%$ người dân chọn các bệnh viên tuyển thành phố và tuyến trung ương để khám chữa bệnh ngoại trú, chỉ có $6 \%$ người tới trạm y tế [2]. 